\title{
Double and Triple Matings Associated with Reproductive Performance in First- Serviced and Reserviced Female Pigs in Commercial Herds
}

\author{
Yasutaka TAKAI ${ }^{1) * *}$ and Yuzo KOKETSU ${ }^{1) *}$ \\ ${ }^{1)}$ School of Agriculture, Meiji University, Kawasaki, Kanagawa 214-8571, Japan
}

(Received 22 February 2008/Accepted 22 January 2009)

\begin{abstract}
The objective of this study was to investigate associations of the number of matings and services with reproductive performance in high-performing and ordinary herds. The data included 113,265 service and 92,248 farrowing records in 117 herds. A service included single or more matings of a female pig (female) during a 10-day estrus period. Two herd groups were built on the basis of the upper 25th percentile of pigs weaned per mated female per year: high-performing ( $\geq 22.8$ pigs) and ordinary herds. Mixed-effects models were used to analyze reproductive performance. Relative frequencies (\%) of single, double and triple or more matings were 3.4, 27.4, and $69.2 \%$ in high-performing herds, respectively, and were 4.6, 59.3 and $36.1 \%$ in ordinary herds, respectively. Percentages of reserviced females in high-performing and ordinary herds were 7.3 and $13.0 \%$, respectively. Triple or more-mated (TM) gilts had 3.5\% higher farrowing rates than double-mated $(\mathrm{DM})$ gilts $(\mathrm{P}<0.01)$, but similar pigs born alive (PBA) to DM gilts in the first service group in both the herd groups. In the first service group, TM sows had $0.8 \%$ higher farrowing rates and 0.2 more PBA than DM sows in high-performing herds $(\mathrm{P}<0.01)$. In the reservice group, TM gilts and TM sows had farrowing rate similar to DM gilts and DM sows in highperforming herds. In conclusion, performing triple matings was a better practice for first-serviced females than performing double matings. Double matings may be sufficient for reserviced females.
\end{abstract}

KEY WORDS: farm management, mating frequency, reservice, sow.

J. Vet. Med. Sci. 71(5): 635-639, 2009

Performing double or triple matings during estrus is a well-recommended practice in commercial swine herds [1, 2]. There is a controversial difference between double and triple matings in subsequent reproductive performance, although timing of mating is critical for maximizing performance [3]. Triple-mated (TM) sows have more pigs born alive (PBA) than double-mated (DM) sows [18]. In contrast, TM sows have PBA similar to DM sows in commercial herds [20]. The impact of the number of matings on economic returns is immense in the swine industry, because a cost of \$10.93 per mating is estimated [9].

Reserviced females have shorter estrus duration, a lower farrowing rate, and more PBA than first serviced females $[15,16]$. However, few studies have reported a difference between reserviced $\mathrm{DM}$ and $\mathrm{TM}$ females in farrowing rate and PBA in commercial herds.

Mating management in high-performing herds is different from that in ordinary herds [8]. Impact of double and triple matings on subsequent reproductive performance may differ between high-performing herds and ordinary herds. Additionally, productivity measurements in high-performing herds are used as improvement goals in swine production to set benchmarks [6, 7]. Mating measurements in high-performing herds can be a benchmark for swine producers [5].

The objectives of this study were to characterize farm

\footnotetext{
* Correspondence to: KoKetsu, Y., Higashimita 1-1-1, Tama-ku, Kawasaki, Kanagawa 214-8571, Japan. e-mail: koket001@isc.meiji.ac.jp

**Present AdDress: TaKaI, Y., Research and Development, Kyodo Shiryo Co., LTD. Higashi-shirakawa, Fukushima 963-5115, Japan.
}

practices of the number of matings and to investigate the associations of the number of matings and the number of services with reproductive performance in high-performing herds and ordinary herds.

\section{MATERIALS AND METHODS}

Data: All producers (approximately 140 herds) in Japan using a recording system (PigCHAMP) were requested to mail their data files to the School of Agriculture, Meiji University, when they renewed their yearly maintenance contract. Annual performance measurements of each herd and reproductive measurements of individual mated females in the year 2002 were obtained from each data file and were used for analyses. The data analyzed in this study were a subset of a larger dataset (116,018 service and 94,200 farrowing records of 54,722 females) from a previous research performed by Takai and Koketsu [17].

Animals and herds: Females in this study herds were F1 crossbreds of Large White and Landrace, or were crossbred pigs purchased from international breeding companies. Both natural mating followed by artificial insemination and natural mating only were commonly practiced when the data were collected.

Exclusion criteria of collected data: Of the total 124 herds, five herds had grow-finish operations and two herds just started. These seven herds were thus excluded, and the remaining 117 herds included 116,018 service and 94,200 farrowing records in 54,722 females. Missing records of farrowing events, the records of sows with lactation length 1-13 and >28 days, sows with weaning-to-first-mating interval $>120$ days and females with reservice intervals 
longer than 150 days (2,753 service and 1,952 farrowing records in 576 females) were considered as extreme, and were excluded [20]. Hence, annual performance measurements in 117 herds, and 113,265 service and 92,248 farrowing records in 54,146 females were used for further analyses.

Definition of production parameters and categorization: A gilt was defined as a female that was present in the herd but not farrowed, and a sow was a female that farrowed at least once. Females included gilts and sows. A mating was defined as any one insemination (mating) of a female during a 10-day estrus period, and a service included single or more mating events during the estrus [11]. A reservice was defined as return to service after service within parity. Mating includes natural mating and artificial insemination.

The number of matings was categorized into three groups: single, double and triple or more matings. The number of services was divided into two groups: first service and reservice. Two herd groups were built on the basis of the upper 25th percentile of pigs weaned per mated female per year [2]: high-performing herds ( $\geq 22.8$ pigs) and ordinary herds $(<22.8$ pigs $)$.

Statistical analysis: All statistical analyses were performed using SAS software, version 9.1 (SAS Inst., Inc., Cary, NC, U.S.A.). The standard error of farrowing rate was obtained by a standard method [12]. Two-level analysis was applied by using a herd at the two-level and an individual record at the one-level [13].

Mixed-effects logistic regression analysis (GLIMMIX procedure) with contrasts was applied for farrowing rate. Linear mixed-effects models (MIXED procedure) with Tukey-Kramer multiple comparisons were applied for continuous data. Gilts and sows were separately analyzed. The chi-squared test was used to compare relative frequencies (\%) of the number of matings among the two herd groups.

Model 1 was built to compare annual performance mea- surements between the two herd groups. Model 2 was constructed to investigate the associations of the number of matings and the number of services with reproductive performance in the two herd groups. The independent variables for gilts were the herd group, the number of matings, the number of services and age at first mating. The independent variables for sows were the herd group, the number of matings, the number of services, parity, lactation length and weaning-to-first-mating interval. All possible two- and three-way interactions between independent variables were included in Model 3, but insignificant interactions $(\mathrm{P}>0.05)$ were removed from the final models.

Models 2 included herd, four periods of three-month intervals and the interaction of the four periods and herd within the herd group as a random effect. The interaction was used to account for a part of correlations of individual services within a female, because once or more services were done in each female during the study year.

\section{RESULTS}

Both gilts and sows in high-performing herds were mated 0.4 more times than those in ordinary herds $(\mathrm{P}<0.05$; Table 1). Relative frequencies (\%) of single, double and triple or more matings were 3.4, 27.4 and 69.2\% in high-performing herds, respectively, and were 4.6, 59.3 and $36.1 \%$ in ordinary herds, respectively. Relative frequencies (\%) of the number of matings in high-performing herds were different from those in ordinary herds in both gilts and sows $(\mathrm{P}<0.05$; Fig. 1). Sows in high-performing herds had 1.2 days shorter weaning-to-first-mating interval than those in ordinary herds $(\mathrm{P}<0.05)$.

In gilts, the herd group, the number of matings and the number of services were associated with farrowing rate $(\mathrm{P}<0.01)$. In addition, the two-way interaction between the number of matings and the number of services was found

Table 1. Reproductive measurements at herd and sow levels in high-performing herds and ordinary herds

\begin{tabular}{|c|c|c|c|c|c|}
\hline \multirow[b]{2}{*}{ Measurements } & \multicolumn{2}{|c|}{ High-performing herds } & \multicolumn{2}{|c|}{ Ordinary herds } & \multirow[b]{2}{*}{$\mathrm{RtR}^{*}$} \\
\hline & $\mathrm{n}$ & Mean & $\mathrm{n}$ & Mean & \\
\hline \multicolumn{6}{|l|}{ Herd measurement } \\
\hline Pigs weaned per mated female per year & 31 & $23.8^{\mathrm{a})}$ & 86 & $20.2^{\mathrm{b})}$ & 1.50 \\
\hline Percentages of reserviced females & 31 & $7.5^{\mathrm{b})}$ & 86 & $13.1^{\mathrm{a})}$ & 4.23 \\
\hline Average female inventory & 31 & 417.1 & 86 & 363.1 & 504.23 \\
\hline \multicolumn{6}{|l|}{ Gilt performance } \\
\hline Number of matings & 6,869 & $2.7^{\mathrm{a})}$ & 17,018 & $2.3^{\mathrm{b})}$ & 0.48 \\
\hline Farrowing rate (\%) & 6,869 & $85.3^{\mathrm{a})}$ & 17,018 & $77.1^{\mathrm{b})}$ & 3.80 \\
\hline Pigs born alive & 5,857 & $10.0^{\mathrm{a})}$ & 13,121 & $9.2^{\mathrm{b})}$ & 2.86 \\
\hline \multicolumn{6}{|l|}{ Sow performance } \\
\hline Number of matings & 25,892 & $2.8^{\mathrm{a})}$ & 63,486 & $2.4^{\mathrm{b})}$ & 0.45 \\
\hline Lactation length (day) & 24,151 & $20.0^{\mathrm{b})}$ & 55,371 & $21.5^{\text {a) }}$ & 1.81 \\
\hline Weaning-to-first-mating interval (day) & 24,147 & $6.2^{\mathrm{b})}$ & 55,346 & $7.4^{\mathrm{a})}$ & 7.34 \\
\hline Farrowing rate (\%) & 25,892 & $87.2^{\mathrm{a})}$ & 63,486 & $79.8^{\mathrm{b})}$ & 2.61 \\
\hline Pigs born alive & 22,586 & $11.0^{\mathrm{a})}$ & 50,684 & $9.9^{\mathrm{b})}$ & 3.00 \\
\hline
\end{tabular}

* RtR $=$ the root residual of the covariance parameter estimate in the mixed model. Pooled SEM would be estimated by the root residual divided by root $n$.

a,b) Values $( \pm$ SEM) within a row with different superscript letters differ $(\mathrm{P}<0.05)$. 
Table 2. Farrowing rate (\%) by the number of matings and the number of services in gilts*

\begin{tabular}{|c|c|c|c|c|}
\hline \multirow[b]{3}{*}{ Number of matings } & \multicolumn{4}{|c|}{ Number of services } \\
\hline & \multicolumn{2}{|r|}{ First service } & \multicolumn{2}{|r|}{ Reservice } \\
\hline & $\mathrm{n}$ & Farrowing rate (\%) & $\mathrm{n}$ & Farrowing rate (\%) \\
\hline Single mating & 1,441 & $70.5 \pm 1.20^{\text {cx) }}$ & 277 & $52.0 \pm 3.01^{\text {by })}$ \\
\hline Double matings & 11,064 & $81.8 \pm 0.37^{\mathrm{bx})}$ & 1,554 & $62.9 \pm 1.23^{\text {ay })}$ \\
\hline Triple or more matings & 8,208 & $85.3 \pm 0.39^{\mathrm{ax})}$ & 1,343 & $59.1 \pm 1.34^{\text {ay) }}$ \\
\hline
\end{tabular}

a-c) Values ( \pm SEM) within a column with different superscript letters differ $(\mathrm{P}<0.01)$.

$\mathrm{x}, \mathrm{y})$ Values $( \pm$ SEM) within a row with different superscript letters differ $(\mathrm{P}<0.01)$.

* Herd comparisons were not shown, because no interaction of the herd groups with the number of matings and the number of services was found with farrowing rate in gilts.

Table 3. Farrowing rate (\%) by the numbers of matings and the number of services in sows in 31 high-performing herds and 86 ordinary herds*

\begin{tabular}{|c|c|c|c|c|}
\hline \multirow[b]{2}{*}{ Groups } & \multicolumn{2}{|c|}{ High-performing herds } & \multicolumn{2}{|c|}{ Ordinary herds } \\
\hline & $\mathrm{n}$ & Farrowing rate (\%) & $\mathrm{n}$ & Farrowing rate (\%) \\
\hline \multicolumn{5}{|l|}{ First service } \\
\hline Single mating & 659 & $76.5 \pm 1.65^{\mathrm{cx})}$ & 2,034 & $70.6 \pm 1.01^{\text {by) }}$ \\
\hline Double matings & 6,595 & $88.4 \pm 0.39^{\mathrm{bx})}$ & 33,180 & $82.5 \pm 0.21^{\mathrm{ay})}$ \\
\hline Triple or more matings & 16,909 & $89.2 \pm 0.24^{\mathrm{ax})}$ & 20,353 & $82.9 \pm 0.26^{\text {ay })}$ \\
\hline \multicolumn{5}{|l|}{ Reservice } \\
\hline \multicolumn{5}{|l|}{ Number of matings } \\
\hline Single mating & 61 & $26.2 \pm 5.67^{\text {by })}$ & 458 & $49.3 \pm 2.34^{\mathrm{cx})}$ \\
\hline Double matings & 370 & $68.4 \pm 2.42^{\mathrm{a})}$ & 4,064 & $65.1 \pm 0.75^{\mathrm{a})}$ \\
\hline Triple or more matings & 1,298 & $68.2 \pm 1.29 \mathrm{a}^{\mathrm{x})}$ & 3,397 & $62.0 \pm 0.83^{\text {by })}$ \\
\hline
\end{tabular}

a-c) Values $( \pm$ SEM) within a column with different superscript letters differ $(\mathrm{P}<0.01)$

$\mathrm{x}, \mathrm{y})$ Values $( \pm$ SEM) within a row with different superscript letters differ $(\mathrm{P}<0.01)$.

* A three-way interaction between the number of matings, herd groups and the number of services was found with farrowing rate $(\mathrm{P}<0.01)$.

with farrowing rate $(\mathrm{P}<0.01$; Table 2$)$. TM gilts had $3.5 \%$ higher farrowing rates than DM gilts in the first service group $(\mathrm{P}<0.01)$, whereas TM gilts had farrowing rate similar to DM gilts in the reservice group in both the herd groups. The first service group had higher farrowing rate than the reservice group, regardless of the number of matings $(\mathrm{P}<0.01)$. No interaction between the herd group and the number of matings was found with farrowing rate.

In sows, the number of matings, the number of services and parity were associated with farrowing rate $(\mathrm{P}<0.01)$. In addition, the three-way interaction between the herd group, the number of matings and the number of services was found with farrowing rate $(\mathrm{P}<0.01$; Table 3$)$. In the first service group, TM sows had $0.8 \%$ higher farrowing rates than DM sows in high-performing herds $(\mathrm{P}<0.01)$, whereas TM sows had farrowing rate similar to DM sows in ordinary herds. In the first service group, high-performing herds had a higher farrowing rate than ordinary herds, regardless of the number of matings $(\mathrm{P}<0.01)$. In the reservice group, TM sows had farrowing rate similar to DM sows in high-performing herds, whereas TM sows had 3.1\% lower farrowing rates than DM sows in ordinary herds $(\mathrm{P}<0.01)$.

TM gilts had PBA similar to DM gilts, whereas TM sows had 0.2 more PBA than DM sows $(\mathrm{P}<0.01$; Table 4$)$. DM and TM gilts and sows had 0.3 pigs or more PBA than sin-
Table 4. Pigs born alive by the numbers of matings in gilts and sows

\begin{tabular}{lrc}
\hline Groups & \multicolumn{1}{c}{$\mathrm{n}$} & Pigs born alive* \\
\hline Gilts & & \\
$\quad$ Number of matings & & \\
$\quad$ Single mating & 1,160 & $9.5 \pm 0.11^{\mathrm{b})}$ \\
$\quad$ Double matings & 10,024 & $9.8 \pm 0.06^{\mathrm{a})}$ \\
$\quad$ Triple or more matings & 7,794 & $9.9 \pm 0.06^{\mathrm{a})}$ \\
$\quad$ Sows & & \\
$\quad$ Number of matings & & \\
$\quad$ Single mating & 2,183 & $10.3 \pm 0.08^{\mathrm{c})}$ \\
$\quad$ Double matings & 36,120 & $10.6 \pm 0.06^{\mathrm{b})}$ \\
$\quad$ Triple or more matings & 34,967 & $10.8 \pm 0.06^{\mathrm{a}}$ \\
\hline
\end{tabular}

a-c) Values ( \pm SEM) within a column with different superscript letters differ $(\mathrm{P}<0.01)$

$\mathrm{x}, \mathrm{y})$ Values $( \pm$ SEM) within a row with different superscript letters differ $(\mathrm{P}<0.01)$.

* Values of pigs born alive are presented as least square means $\pm \mathrm{SE}$. Herd comparisons were not shown, because no interaction of the herd groups with the number of matings and the number of services was found with pigs born alive in gilts and sows.

gle-mated gilts and sows $(\mathrm{P}<0.05)$. The three-way interaction between the herd group, the number of matings, and the number of services with PBA was not found in gilts and sows. 

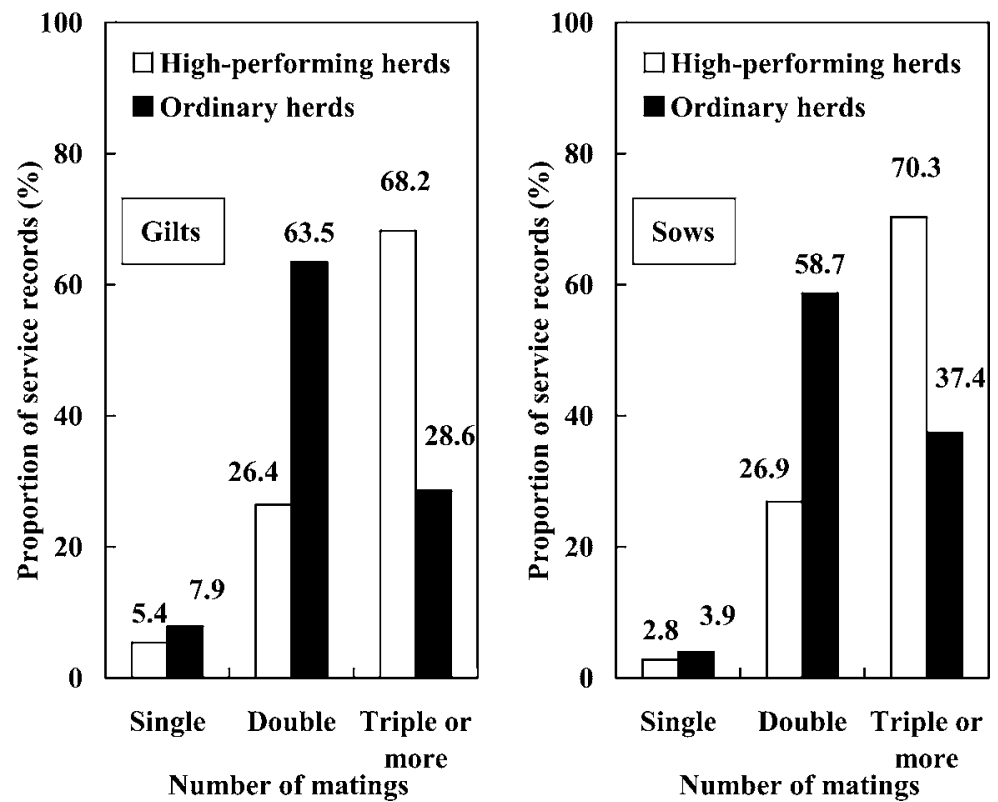

Fig. 1. Relative frequencies (\%) of the number of matings in gilts and sows by 31 high-performing herds and 86 ordinary herds. Relative frequencies (\%) of the number of matings in high-performing herds were different from those in ordinary herds $(\mathrm{P}<0.05)$.

\section{DISUCUSSION}

Approximately $70 \%$ of females were mated triple or more times in high-performing herds, whereas approximately 36\% were TM females in ordinary herds. This difference in the number of matings can be explained by a difference in mating management between the herd groups such as heat detection and mating schedule. Longer weaning-to-firstmating interval in ordinary herds than that in high-performing herds may also be related to short estrus duration, because an increase in weaning-to-estrus interval decreased duration of estrus [3]. For example, sows with short estrus duration may be triple-mated in high-performing herds, but those sows may be only double-mated in ordinary herds.

In the first service group, TM sows had higher farrowing rate than DM sows in high-performing herds, whereas TM sows had farrowing rate similar to DM sows in ordinary herds. This finding indicated that TM sows in high-performing herds were mated on better timing of mating relative to ovulation due to accurate estrus detection than those in ordinary herds. The high fertilization results can be achieved in sows that were mated between 0 and $24 \mathrm{hr}$ before ovulation [14]. Our study also showed that TM sows had 0.2 more PBA than DM sows in both the herd groups. Triple matings were a better practice than double matings in high-performing herds when the data were collected. This finding was supported by the proposed mating schedule with artificial inseminations at 12, 24, and $36 \mathrm{hr}$ after the first detection of estrus in order to yield the highest economic returns in a simulation study [10].
Our study also revealed that performing double and triple matings in reserviced females yielded similar farrowing rates in high-performing herds, but DM reserviced females had a higher farrowing rate than TM females in ordinary herds. Reserviced females might have an optimal timing of mating different from first serviced females, because reserviced females had shorter estrus duration and earlier ovulation timing than first-serviced females $[14,16]$. The timing of mating for reserviced females in ordinary herds may be detected less accurately than that in high-performing herds.

For optimal economic returns, performing double matings is better than triple matings when double matings produce reproductive performance similar to triple matings. Producers in the present study are currently recommended to sharpen their mating management to perform double matings on optimal timing. An accurate detection of an initial stage of the estrus period in sows is critical for estimating the moment of ovulation and for pinpointing the mating [4]. Estrus detection should be also frequently performed with a matured boar, because the presence of a boar induced high pulse frequency of LH and long estrus duration [10, 19].

In conclusion, performing triple matings during estrus is a better practice for first-serviced gilts and sows than performing double matings. Performing double matings may be sufficient in case of reserviced females.

Limitations of the present study are that herd health, genetics and mating management including a ratio of artificial insemination and natural mating, which we did not measure, could lead to biased results in this observational study. However, even with such limitations, the present study pro- 
vides veterinarians and producers with useful information on mating frequency to improve female performance in commercial herds.

ACKNOWLEDGEMENTS. Appreciation is expressed to cooperative producers for providing their records and the staff in Global Pig Farms Inc. (Shibukawa, Gunma, Japan) for their technical assistance. This research is supported by Research Project Grants from Meiji University and the Ministry of Education, Culture, Sports, Science and Technology of Japan.

\section{REFERENCES}

1. Corrêa, M. N., Lucia Jr, T., Afonso, J. A. B. and Deschamps, J. C. 2002. Reproductive performance of early-weaned female swine according to their estrus profile and frequency of artificial insemination. Theriogenology 58: 103-112.

2. Dial, G. D., Marsh, W. E., Polson, D. D. and Vaillancourt, J. P. 1992. Reproductive failure: differential diagnosis. pp. 88-137. In: Diseases of Swine (Leman, A. L., Straw, B. E., Mengeling, W, L., D'Allaire, S. and Taylr, D. J. eds.), Iowa State University Press, Ames.

3. Kemp, B. and Soede, N. M. 1996. Relationship of weaning-toestrus interval to timing of ovulation and fertilization in sows. J. Anim. Sci. 74: 944-949.

4. Kemp, B., Steverink, D. W. B. and Soede, N. M. 1998. Herd management in sows: optimizing insemination strategies. Reprod. Dom. Anim. 33: 159-164.

5. King, V. L., Koketsu, Y., Reeves, D., Xue, J. and Dial, G. D. 1998. Management factors associated with swine breedingherd productivity in the United States. Prev. Vet. Med. 35: 255-264.

6. Koketsu, Y. 2000. Productivity characteristics of high-performing commercial swine breeding farms. J. Am. Vet. Med. Assoc. 216: 376-379.

7. Koketsu, Y. 2002. Reproductive productivity measurements in Japanese swine breeding herds. J. Vet. Med. Sci. 64: 195-198.

8. Koketsu, Y. 2005. Six component intervals of nonproductive days by breeding-female pigs on commercial farms. J. Anim.
Sci. 83: 1406-1412.

9. Lamberson, W. R. and Safranski, T. J. 2000. A model for economic comparison of swine insemination programs. Theriogenology 54: 799-807.

10. Langendijk, P., Bouwman, E. G., Schams, D., Soede, N. M. and Kemp, B. 2003. Effects of different sexual stimuli on oxytocin release, uterine activity and receptive behavior in estrous sows. Theriogenology 59: 849-861.

11. PigCHAMP. 1996. PigCHAMP Reports Manual. University of Minnesota, St. Paul.

12. Rosner, B. 1989. Fundamentals of biostatistics (3rd ed.), PWSKent Publishing Co., Boston, MA.

13. Singer, J. D. 1998. Using SAS PROCMIXED to fit multilevel models, hierarchical models, and individual growth models. $J$. Educ. Behav. Stat. 24: 323-355.

14. Soede, N. M., Wetzels, C. C. H., Zondag, W., de Koning, M. A. I. and Kemp, B. 1995. Effects of insemination relative to ovulation, as determined by ultrasonography, on fertilization rate and accessory sperm count in sows. J. Reprod. Fertil. 104: 99-106.

15. Sterning, M. and Lundeheim, N. 1995. Some factors influencing pregnancy rate and subsequent litter size in primiparous sows. Acta Vet. Scand. 36: 353-365.

16. Steverink, D. W. B., Soede, N. M., Groenland, G. J. R., van Schie, F. W., Noordhuizen, J. P. T. M. and Kemp, B. 1999. Duration of estrus in relation to reproduction results in pigs on commercial farms. J. Anim. Sci. 77: 801-809.

17. Takai, Y. and Koketsu, Y. 2007. Identification of a female-pig profile associated with lower productivity on commercial farms. Theriogenology 68: 87-92.

18. Tilton, J. E. and Cole, D. J. A. 1982. Effect of triple versus double mating on sow productivity. Anim. Prod. 34: 279-282.

19. Van den Wiel, D. F. M. and Booman, P. 1993. Post-weaning anoestrus in primiparous sows: LH patterns and effects of gonadotropin infection and boar exposure. Vet. Quart. 15: 162-166.

20. Xue, J., Lucia, T., Koketsu, Y., Dial, G. D. and Marsh, W. E. 1998. Effect of mating frequency and weaning-to-mating interval on sow reproductive performance. Swine Health Prod. 6: 157-162. 